\title{
Optogenetic olfactory behavior depends on illumination characteristics
}

\author{
Tayfun Tumkaya ${ }^{1,2,3,4}$, James Stewart', Safwan B. Burhanudin', Adam Claridge-Chang 1,2,3,4 \\ 1. Institute for Molecular and Cell Biology, A*STAR, Singapore 138673 \\ 2. Department of Physiology, National University of Singapore, Singapore \\ 3. Program in Neuroscience and Behavioral Disorders, Duke-NUS Medical School, Singapore \\ 4. Correspondence
}

\begin{abstract}
Optogenetics has become an important tool for the study of behavior, enabling neuroscientists to infer causations by examining behavior after activating genetically circumscribed neurons with light. Light-induced neural activity is affected by illumination parameters used in experiments, such as intensity, duration, and frequency. Here, we hypothesized that the intensity of light and the presence of oscillations in illumination would alter optogenetically induced olfactory behaviours. To test this, we activated olfactory receptor neurons (ORNs) in Drosophila by using either static or pulsed light stimuli across a range of light intensities. The various regimes elicited distinct behavioral valence responses (attraction, aversion, indifference) from several ORN types. Our results demonstrate the importance of both frequency and intensity for interpreting optogenetic behavioral experiments accurately; successfully generalizing optogenetic results requires the use of more than a single illumination regime.
\end{abstract}




\section{Introduction}

For scientific research, interventional methods have been central to establishing causal relationships (Lewin, 1947; Midgley, 2003; Miesenböck \& Kevrekidis, 2005; Thiese, 2014). Genetic lesion studies, for example, are critical to determine gene function (Baratz et al., 2010; Chong et al., 2015; Katsanis, 2016; Muenke et al., 1994). Similarly, neuronal activation and inhibition experiments identify links between behaviours and neurons (Bernstein \& Boyden, 2011; Deisseroth, 2015; Fenno, Yizhar, \& Deisseroth, 2011; Packer, Roska, \& Häusser, 2013). For analyzing the function of neural circuits, optogenetic activation has become one of the most-used techniques.

Using light to actuate photosensitive proteins that are encoded by DNA enables neuroscientists to rapidly manipulate genetically circumscribed neurons (Miesenböck, 2009). Following pioneering methods used to control neuronal function with light (Banghart, Borges, Isacoff, Trauner, \& Kramer, 2004; Lima \& Miesenböck, 2005; Szobota et al., 2007; Volgraf et al., 2006; Zemelman, Lee, Ng, \& Miesenböck, 2002; Zemelman, Nesnas, Lee, \& Miesenbock, 2003), the microbial opsins have found the widest application in optogenetics (Deisseroth, 2015; Fenno et al., 2011). Microbial opsins are photosensitive seven-transmembrane proteins, typically ion pumps, channel proteins, or regulators of ion channels. Upon light activation, they modulate transmembrane voltage (Fenno et al., 2011; Miesenböck, 2009). The blue-light sensitive cation channel Channelrhodopsin-2 (Chr2) was the first microbial opsin used to control neuronal activity (Boyden, Zhang, Bamberg, Nagel, \& Deisseroth, 2005). Chr2 has been iteratively engineered for improved photoconductivity, as well as for diverse wavelength sensitivities (Deisseroth, 2010; Guru, Post, Ho, \& Warden, 2015; Lin, 2011). A multitude of the Chr2 variants have been used in vivo in animal models-such as Drosophila, zebrafish, C. elegans, and mice-to activate neurons and study behavior (Fenno et al., 2011). 
The action potential of an optogenetically activated neuron is mainly determined by biophysical properties of the opsin, as well as characteristics of the light stimulus: pulse intensity, width, duration, and frequency (Boyden et al., 2005; Miesenböck, 2011; Mohanty \& Lakshminarayananan, 2015). Ideally, illumination protocols are optimized to make artificial action potentials similar to the natural activity (Allen, Singer, \& Boyden, 2015; Packer et al., 2013). However, there are no overall guidelines for picking light parameters for optogenetics experiments; as a consequence, illumination protocols vary greatly across studies (Herman, Huang, Murphey, Garcia, \& Arenkiel, 2014; Mattis et al., 2011). How does the light-stimulus variability affect optogenetically induced behaviours?

Here, we addressed this question with the optogenetic actuation of Drosophila olfactory behaviour. Flies may produce directed locomotion responses (attraction or aversion) to optogenetic activation of single classes of olfactory receptor neurons (ORNs) (Bell \& Wilson, 2016). In a custom-built behavioral assay, we tested the attraction or aversion valence to optogenetic activation of four classes of olfactory neurons (the ORNs expressing Or59c, Or85c, Or92a and the $\mathrm{CO}_{2}$-sensitive gustatory receptor neuron expressing Gr21a) by using either static or pulsed light stimulus at three different intensities. In all four cases, the valence responses to pulsed light were dramatically different to that of static light. Moreover, olfactory responses considerably varied across the different light intensities. Despite using the same opsin and behavioral assay to activate the exact same set of neurons, different light intensities and frequencies gave rise to distinct conclusions. These results reveal that the temporal structure of optogenetic light has a large impact of behavioral outcomes, and suggests that experiments using a single parameter may not be generalizable. 


\section{Material and methods}

\section{Fly care and strains}

Flies were prepared as previously described (Mohammad et al., 2017). Briefly, flies were kept in the dark on a regular fly medium (Temasek Life Sciences Laboratories, 2018), and transferred on $0.5 \mathrm{mM}$ all-trans-retinal (Sigma-Aldrich, USA) supplemented food two days prior to optogenetic experiments. Cantonized $w^{1118}$ flies were used as wild type. The ORN-Gal4 (Couto, Alenius, \& Dickson, 2005; Fishilevich \& Vosshall, 2005) and UAS-CsChrimson (Klapoetke et al., 2014) stocks were obtained from the Bloomington Drosophila Stock Center. All flies used in the study were starved on $2 \%$ agarose for $12-18$ hours prior to the experiments.

\section{Optogenetic behavior apparatus}

An optogenetic apparatus was designed somewhat similar to one previously described (Mohammad et al., 2017). A rectangular arena $(11.5 \times 14.5 \times 0.3 \mathrm{~cm})$ was cut out of an acrylic board with 16 tracks $(50 \times 4 \mathrm{~mm})$ carved on it to place flies. The arena was kept in an incubator to maintain a dark and $25^{\circ} \mathrm{C}$ degrees environment during experiments. Six red LEDs (617 nm; Luxeon Rebel LEDs on a SinkPAD-II $10 \mathrm{~mm}$ Square Base) glued on heat sinks were placed above the arena at a $\sim 45$ angle on both sides. The LEDs were equipped with optic lenses (17.7 $10 \mathrm{~mm}$ Circular Beam Optic) and powered with 700-mA BuckPuck drivers. With the aid of masks cut from black acrylic, separate control of the LEDs on each side allowed to illuminate red light on either half of the arena. The red LEDs were controlled by custom software, CRITTA (Mohammad et al., 2016). The light intensity was measured by using a thermal power sensor (Thorlabs S310C) connected to a power and energy-meter console (Thorlabs PM100D). Two grids of infrared LEDs illuminated the platform for an AVT Guppy PRO F046B camera, which was equipped with an IR bandpass filter (Edmund Optics, Singapore), to monitor flies. The camera streamed video to the CRITTA software to detect fly positions in real-time. The fly-position data were logged in text files for offline analysis. 


\section{Optogenetic Self-Administration Response (OSAR) assays}

Flies were collected 2-3 days prior to the experiments.

They were loaded into the chambers after being anesthetized by a 30 -sec ice treatment. The experimental procedure consisted of acclimatization of flies for $30 \mathrm{~s}$, illumination of left half of the arena for $45 \mathrm{~s}$, a recess of 30 $\mathrm{s}$, illumination of right half of the arena for $45 \mathrm{~s}$, and a final interval of $30 \mathrm{~s}$ to ensure a consistent breaks between the experiments. Each group of flies was tested at three intensities-4.65, 9.3, $14 \mu \mathrm{W} / \mathrm{mm}^{2}$-either in static or pulsed ( $20 \mathrm{~Hz}, 50 \%$ duty cycle) light. The frequency for pulsed light was chosen following a previously published method (Bell \& Wilson, 2016), and the pulsed light was normalized to have the same intensity as the static light.

\section{OSAR data analysis: wTSALE metric}

Fly position data recorded by the CRITTA software were analyzed by custom-built Python scripts. The light preference of flies is determined by analyzing the proportion of time they spend in the illuminated zone once they discovered it. We termed this metric Time Spent After Light Encounter (TSALE). Given that some flies discover the light from the start, and some never do, we weighted TSALE linearly with a number ranging from 0 to 1: flies that never encountered the light could not inform us about the light preference and had a weight of 0 ; flies who discovered the light from the start provided the most insight and weighted by 1 (weighted-TSALE; wTSALE). The wTSALE score was calculated for each fly, and then averaged for control and test genotypes. The mean difference between the control and test groups was taken as the effect size ( $\triangle$ WTSALE); mean difference distributions and $95 \%$ bootstrapped confidence intervals (Cls) were calculated by using the DABEST Python package (Ho, Tumkaya, Aryal, Choi, \& Claridge-Chang, 2018), and presented in the following format: 'mean $[95 \mathrm{Cl}$ lower bound, upper bound].' 


\section{Data and code availability}

The Python scripts used to analyze fly tracking data are available on GitHub at 'https://github.com/ttumkaya/WALiSuite_V2.0', as well as on the Zenodo server at 'zenodo.2540290'. All the tracking data can be found on the Zenodo server at 'zenodo.2541462'.

\section{Results}

\section{Triggering valence with optogenetic activation}

Artificial activation of single classes of Drosophila sensory neurons has been shown to be able to drive valent behavior: attraction or aversion, depending on the neuronal type (Bell \& Wilson, 2016; Hernandez-Nunez et al., 2015; Suh et al., 2007). To examine the valent behavior elicited by olfactory-neuron activation, we used a behavioral assay in which flies can be given a choice between red light or no light; we refer to it as the Optogenetic Self-Administration Response (OSAR) assay (Fig 1A). Transgenic flies that express a red-light-sensitive cation channel, CsChrimson (Chr), in neurons of interest are loaded in the OSAR arena. Flies can either spend increased time in the red light, avoid it, or display indifferent behavior. We calculated the relative valence of activation by measuring how much time flies spent in red light after they first encountered it (Fig 1B). To test the hypothesis that the characteristics of optogenetic light stimulus influence the behaviour, we used either pulsed light at $20 \mathrm{~Hz}$ (Bell \& Wilson, 2016) or static illumination at three light intensities. 
A

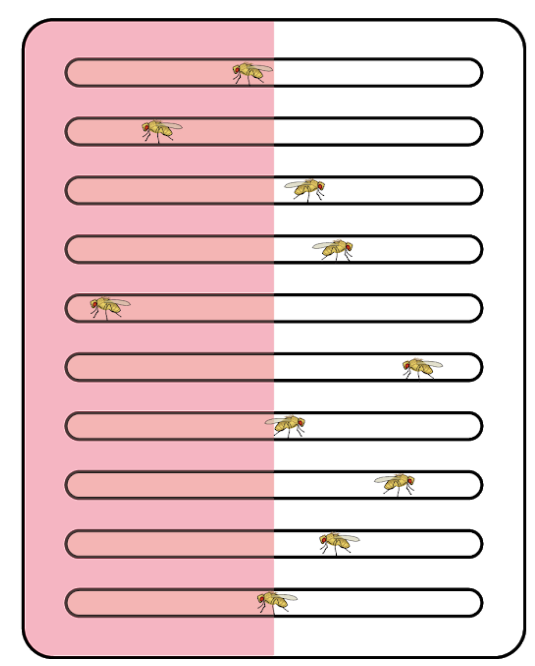

B

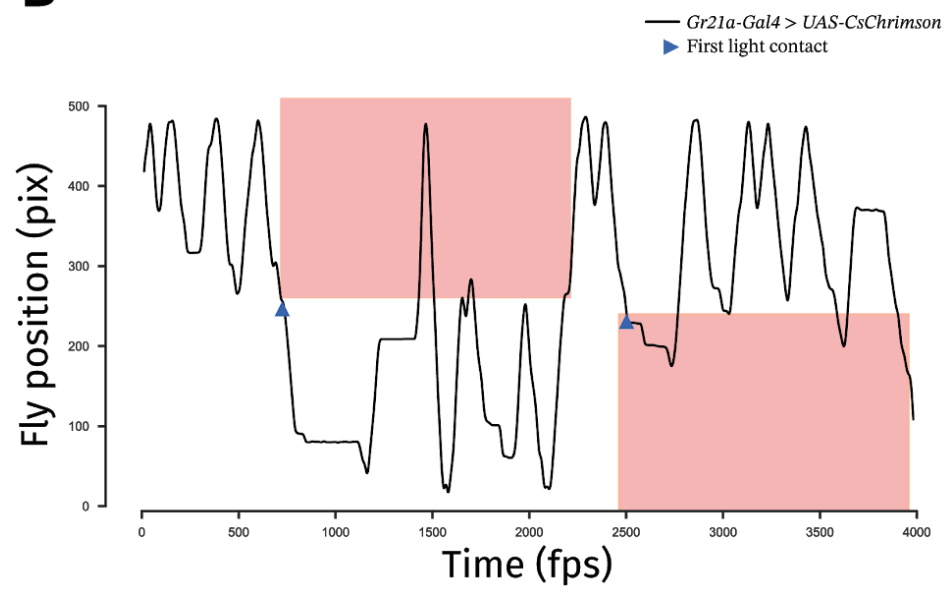

Figure 1. The Optogenetic Self-Administration Response (OSAR) assay

A. Flies are loaded in a darkened arena and given a choice between red light and dark.

B. An example trace of a fly that spends most of its time in the dark zones after encountering red light (blue arrows). Red boxes indicate when the fly is walking through red illumination.

\section{Flies avoid pulsed activation of Gr21a neurons}

For Drosophila, $\mathrm{CO}_{2}$ acts a stress odor and triggers an avoidance response (Suh et al., 2004). The gustatory receptor Gr21a is one of the two receptors that mediate $\mathrm{CO}_{2}$ aversion (Jones, Cayirlioglu, Kadow, \& Vosshall, 2007; Kwon, Dahanukar, Weiss, \& Carlson, 2007; Suh et al., 2004). Artificial activation of Gr21a neurons is sufficient to elicit avoidance (Suh et al., 2007). Here, we tested Gr21a avoidance by optogenetically activating these neurons with either static or pulsed light. While continuous photoactivation was aversive only at the lowest light intensity (4.65 $\mu \mathrm{W} / \mathrm{mm}^{2}$, Fig $\left.2 \mathrm{~A}\right)$, pulsed light triggered aversion at all three intensities (Fig 2B). This dramatic behavioral difference between static- and pulsed-light activations indicates that the presence or absence of oscillations can alter the behavioral effect of optogenetic actuation (Fig 2C). 

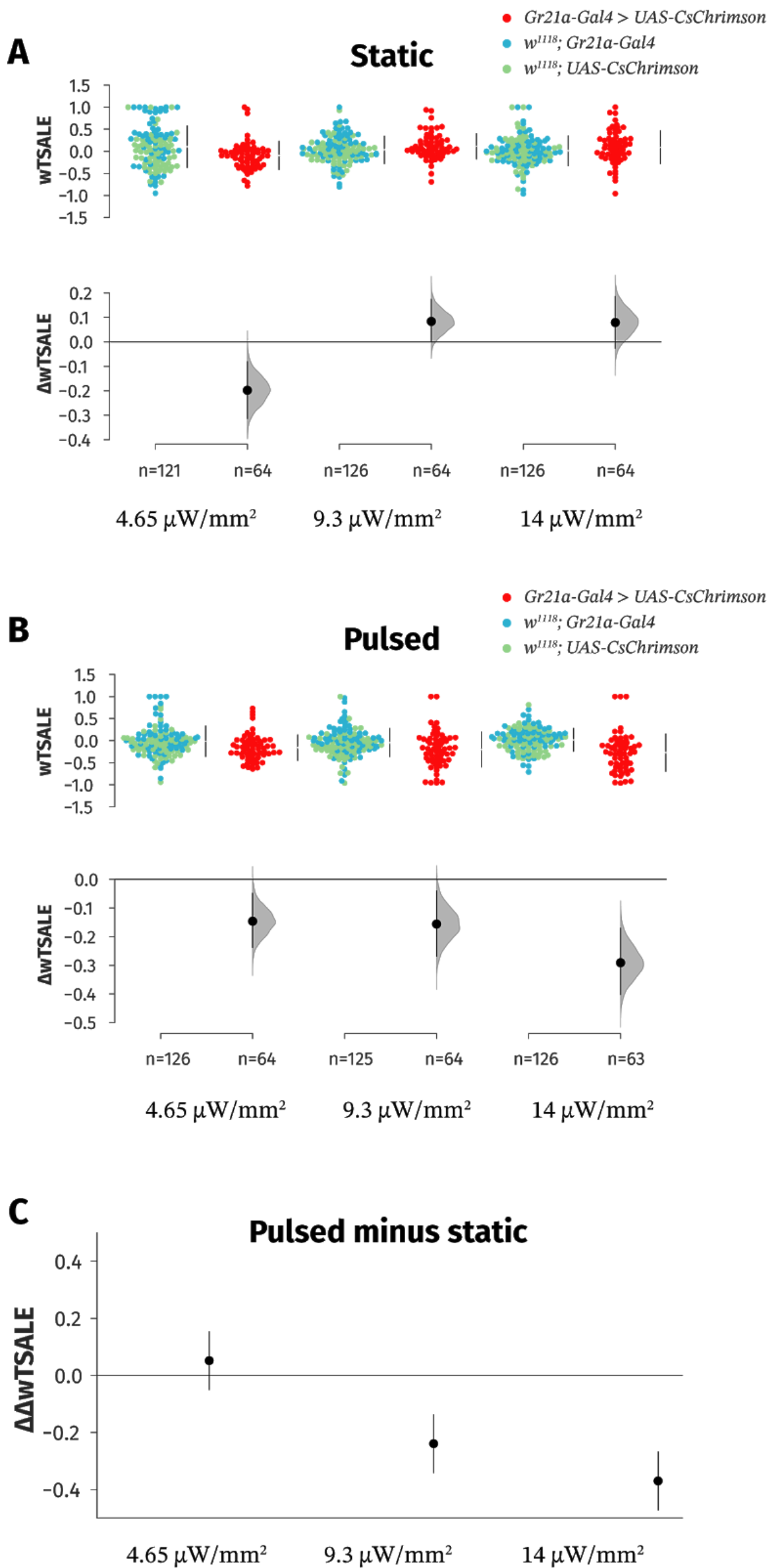


\section{Figure 2. Pulsed-light and static-light stimulation of the Gr21a neurons triggers distinct responses}

A. In static light, flies bearing the red-light-shifted opsin $\mathrm{Chr}$ in the $\mathrm{CO}_{2}$-sensitive $\mathrm{Gr} 21 \mathrm{a}$ neurons spent less time in red light only at the lowest light intensity $\left(4.65 \mu \mathrm{W} / \mathrm{mm}^{2}\right)$ relative to the parental controls. Upper plot illustrates the amount of time flies spent in red light, where the dots represent single flies. Test flies are shown in red (Gr21a-Gal4 > UAS-CSChrimson) and controls shown in blue and green, respectively ( $w^{1118}$; Gr21a-Gal4 and $w^{1118}$;UAS-CSChrimson). Lower plot indicates the mean wTSALE difference. All error bars are 95\% Cls.

B. When pulsed light used to stimulate the Gr21a neurons, test flies avoided red-light illuminated zones at all three light intensities $\left(4.65,9.3,14 \mu \mathrm{W} / \mathrm{mm}^{2}\right)$ compared to parental controls.

C. The differences between static- and pulsed-light regimes show that pulsed stimulation of the Gr21a neurons elicits stronger aversion in the two higher light intensities $(9.3,14$ $\left.\mu \mathrm{W} / \mathrm{mm}^{2}\right):-0.24[95 \mathrm{Cl}-0.14,-0.34]$ and -0.37 [95Cl $\left.-0.48,-0.26\right]$, respectively.

\section{Static-light activation of vinegar-sensing neuron evokes attraction}

Unsurprisingly, vinegar flies are strongly attracted to vinegar. Vinegar has been shown to activate six glomeruli in the Drosophila brain, two of which are sufficient to produce the attraction behavior: Or42b and Or92a (Semmelhack \& Wang, 2009). Static- and pulsed-light optogenetic activations of Or92a induced different behaviors: static-light activation became increasingly attractive in the two higher light intensities (9.3, 14 $\mu \mathrm{W} / \mathrm{mm}^{2}$, Fig $\left.3 \mathrm{~A}\right)$, whereas pulsed light did not trigger any behavioral response (Fig 3B). The discrepancy between the two types of light stimuli is largest at the highest light intensity with a $\triangle \mathrm{WTSALE}$ of -0.22 [95Cl $-0.35,-0.09]$ (Fig 3C). 

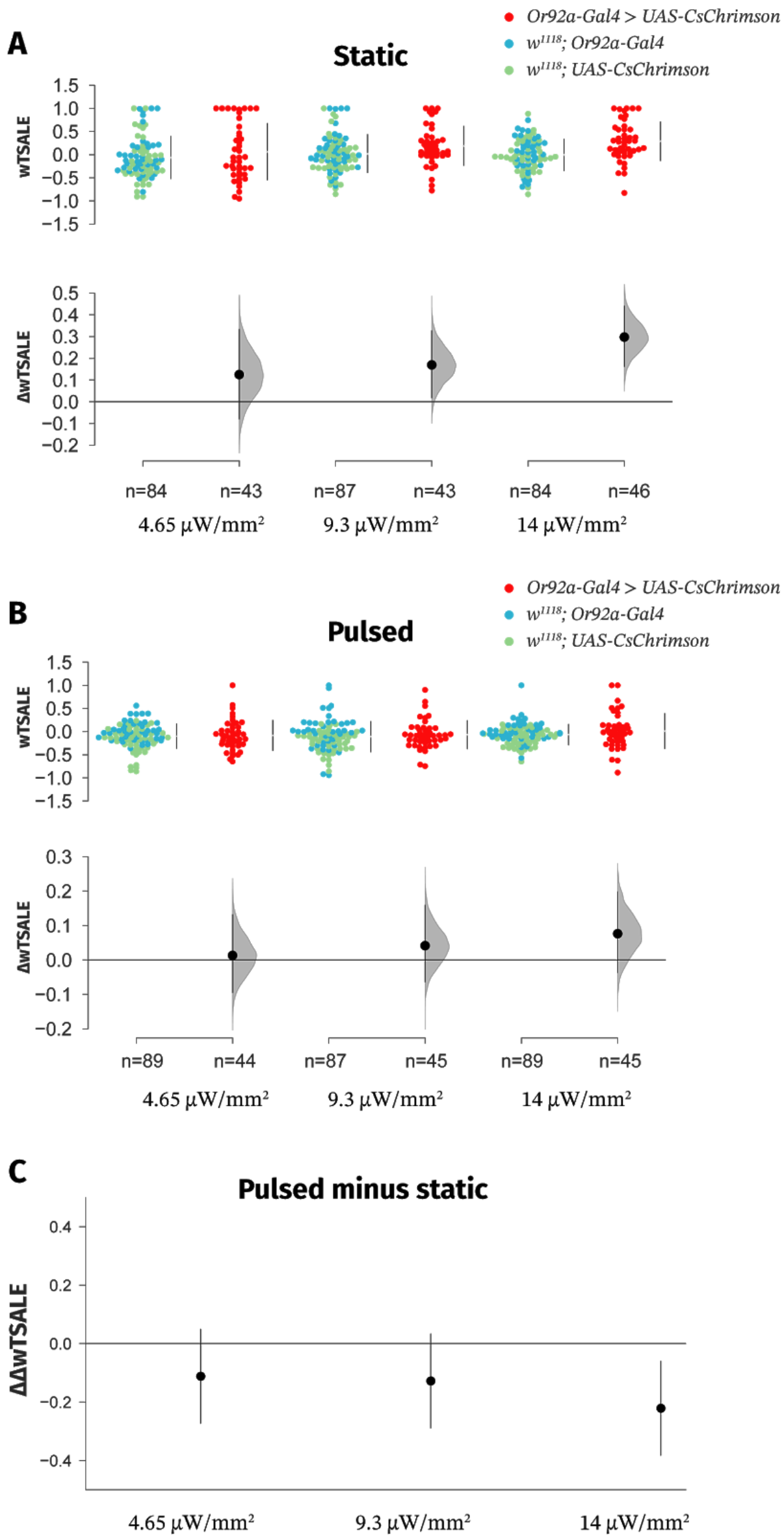
Figure 3. Only static illumination of the vinegar-sensitive neuron Or92a triggers attraction

A. Static-light stimulation of the Or92a neurons is attractive to the flies at intensities of 9.3 and $14 \mu \mathrm{W} / \mathrm{mm}^{2}$.

B. Activating the Or92a neurons with pulsed light elicits only minor valence responses.

C. The amount of time spent in red light decreases by $-0.22[95 \mathrm{Cl}-0.35,-0.09]$ in the highest light intensity when pulsed-light is used.

\section{Static- and pulsed-light activations of Or59c and Or85c} elicit distinct valence responses

Of the $\sim 60$ types odor receptors expressed in the fly head, innate valence properties have been tested for a subset (Bell \& Wilson, 2016). We tested two receptors (Or59c and Or85c) with unknown valence responses. Stimulation of the Or59c receptor neurons with static light produced strong aversion at the lowest light intensity (Fig 4A); the effect was markedly lower in the pulsed-light stimulation (Fig $4 \mathrm{~B}-\mathrm{C}$ ). For the Or85C receptor neurons, while static light did not elicit any valence (Fig 4D), pulsed-light activation evoked aversion in the two lower light intensities (Fig $4 \mathrm{E}-\mathrm{F})$. These results further validated that static- and pulsed-light stimuli may elicit considerably different behavioral responses. 
A
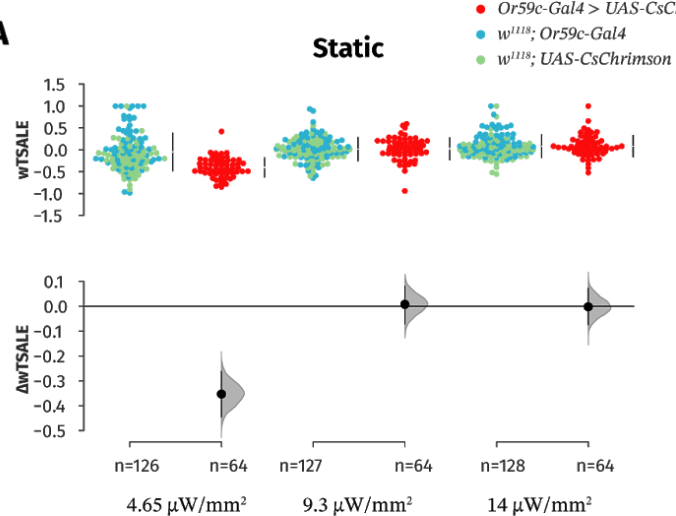

B

- Or59c-Gal4> UAS-CsChrimson
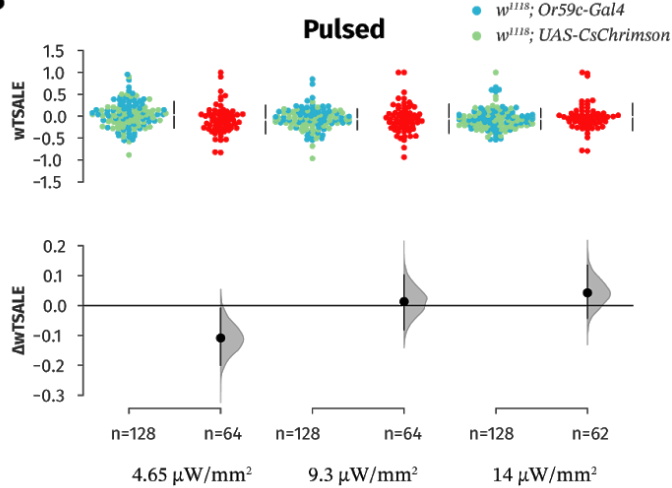

C

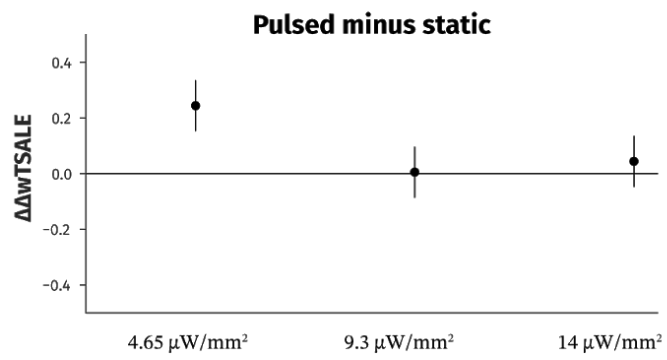

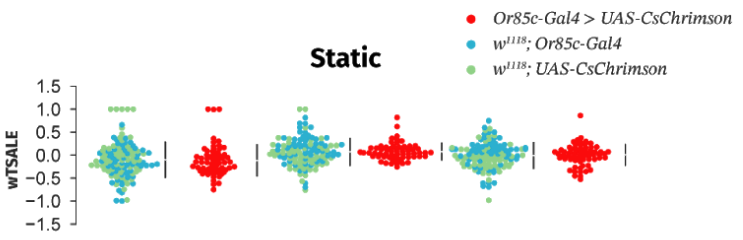

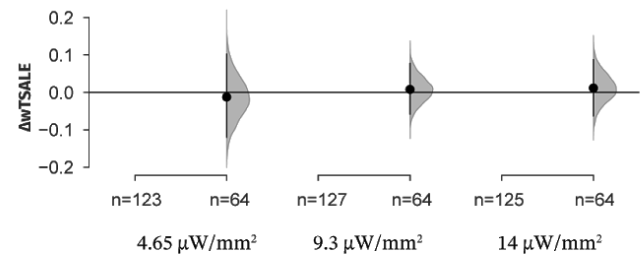

$\mathbf{E}$
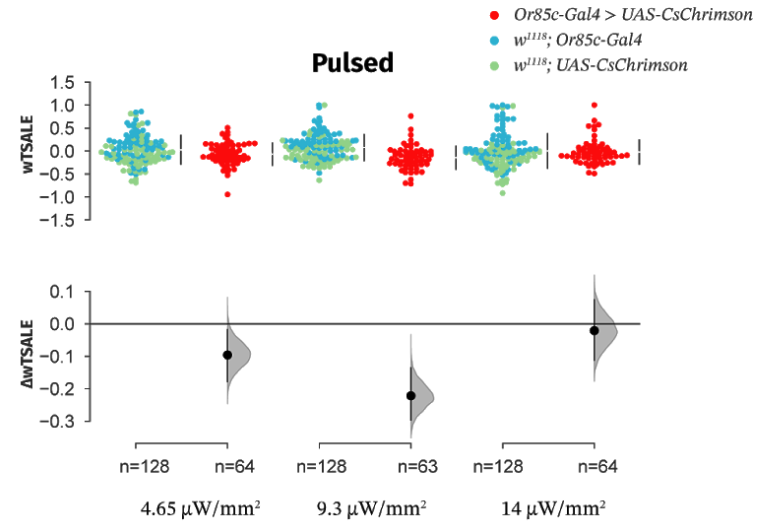

$\mathbf{F}$

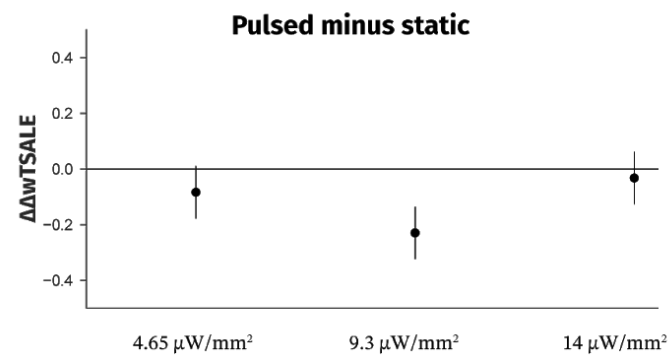

Figure 4. Static and pulsed light stimulations evoke different valence responses in Or59c and Or85c neurons

A. Static-light stimulation of the Or59c neurons is strongly aversive at the lowest intensity $4.65 \mu \mathrm{W} / \mathrm{mm}^{2}$.

B. Pulsed-light stimulation of the Or59c neurons is aversive at the lowest intensity 4.65 $\mu \mathrm{W} / \mathrm{mm}^{2}$.

C. Pulsing the light stimulus reduced the Or59c-induced aversion by a wTSALE of 0.24 [95CI $0.15,0.34]$ at $4.65 \mu \mathrm{W} / \mathrm{mm}^{2}$.

D. Static-light stimulation of the Or85c neurons does not elicit any valence response.

E. Pulsed-light stimulation of the Or85c neurons is aversive at the two lower intensities.

F. Static and pulsed-light stimulations of the Or85c neurons elicit substantially different valences at two lower light intensities: $-0.08[95 \mathrm{Cl}-0.18,0.00]$ and $-0.23[95 \mathrm{Cl}-0.30,-0.16]$, respectively. 


\section{Discussion}

\section{Optogenetic temporal structure influences olfactory-related behavior}

Vinegar and $\mathrm{CO}_{2}$ are important cues for Drosophila to find food and sense stress (Jones et al., 2007; Semmelhack \& Wang, 2009; Suh et al., 2004). Optogenetic activation of vinegar- and $\mathrm{CO}_{2}$-sensing cells (the Or92a and $\mathrm{Gr} 21 \mathrm{a}$ neurons, respectively) reproduced the natural approach and avoidance responses triggered by their corresponding ligands. However, the temporal dynamics that elicited ligand-type responses were different for the two sets of neurons: Gr21a-neuron aversion occured in response to pulsed light, while vinegar-responsive Or92a neurons drove attraction in response to static illumination. A simple explanation of this disparity is that the olfactory system uses both ORN identity and rate to drive behavior (van Breugel, Huda, \& Dickinson, 2018). The Gr21a neurons have been shown to respond to rapid changes in $\mathrm{CO}_{2}$ concentration levels, while vinegar-sensitive neurons encode intermittent signals poorly (Faucher, Hilker, \& de Bruyne, 2013). Thus, even though the pulse frequency is similar to the action-potential frequencies observed during odor responses (Bell \& Wilson, 2016), it seems likely that pulsed-light stimulation of the Or92a neurons generated activity patterns are distinct from vinegar exposure.

Static- and pulsed-light stimulations induced distinct behaviours through Or59c and Or85c neurons as well: static light triggered the strongest avoidance response from the Or59c neurons; conversely, only pulsed light elicited an avoidance response from the Or85c neurons, but not static light (Fig 4A-F). Interestingly, all of the olfactory responses induced by Or59c and Or85c neurons occured at the lower light intensities (Fig 4A-B-E), and did not increase as the light intensity increased.

Of the four ORNs tested in the present study, static-light stimulation performed better in eliciting olfactory responses than the pulsed light for two ORNs (Or92a, 
Or59c); and the opposite was true for the other two ORNs (Gr21a, Or85c). These results suggest that neither stimulation type is necessarily superior to the other: static- or pulsed-light stimulation can capture more of the native responses than the other in inducing olfactory behavior, depending on the neuronal type.

\section{Temporal structure is relevant to optogenetic input in a range of circuits}

ORNs are not the only neurons that drive different behaviors in response to different optogenetic activation patterns (Clark et al., 2018). An examination of crawling behaviour in the Drosophila larvae used activation of motor neurons with either Channelrhodopsin-2 (Chr2) or a mutant variant of it, $\mathrm{Chr}^{\mathrm{H} 134 \mathrm{R}}$, that has increased responsiveness to light stimulation (Nagel et al., 2005; Pulver, Pashkovski, Hornstein, Garrity, \& Griffith, 2009). Static or pulsed light was used to actuate the opsins: neither affected the behaviour when the motor neurons express Chr2; as for the Chr2 ${ }^{\mathrm{H} 134 \mathrm{R}}$ variant, only static light affected crawling behaviour, and not pulsed light. Two recent studies found discrepant effects on sleep when the galanin neurons in the mouse ventrolateral preoptic area were activated at different frequencies: activation at higher frequencies increased wakefulness (Chung et al., 2017), while lower frequencies $(0.5-4 \mathrm{~Hz})$ promoted sleep (Kroeger et al., 2018). Electrophysiology recordings have consistently shown that various light-stimulus parameters have various effects on optogenetically targeted neurons (Boyden et al., 2005; Klapoetke et al., 2014; Mattis et al., 2011; Pulver et al., 2009), and growing evidence now shows that light parameters also change optogenetically induced behaviours.

\section{Should optogenetic activation mimic natural activity?}

The extent to which optogenetic activation needs to mimic natural neuronal activity to recreate natural behaviors is not clear (Malyshev, Goz, LoTurco, \& Volgushev, 2015; Miesenböck, 2009). Unstructured optogenetic activation has successfully elicited complex behaviours in model 
animals: courtship behaviour (Clyne \& Miesenböck, 2008), olfactory learning in flies (Claridge-Chang et al., 2009); swimming behaviour in zebrafish (Wyart et al., 2009); awakening (Adamantidis, Zhang, Aravanis, Deisseroth, \& de Lecea, 2007) and learning in mice (Huber et al., 2008). On the other hand, some behaviours, such as odor information processing in zebrafish (Blumhagen et al., 2011) and in mice (Haddad et al., 2013; Smear, Shusterman, O'Connor, Bozza, \& Rinberg, 2011), have been shown to be highly dependent on temporal structure. Mounting evidence, including the present study, indicates that different photostimulation regimes produce distinct behaviours (Chung et al., 2017; Kroeger et al., 2018; Pulver et al., 2009). Overall, our findings support the idea that, to inform generalizable conclusions about a neural system, a single optogenetic regime will often be inadequate. As there is no one-size-fits-all guide for choosing light parameters, using multiple intensities and frequencies will be prudent when characterizing systems with optogenetic activation.

\section{Conclusions}

Optogenetics has been extensively used to study behavior; however, the extent to which illumination protocols influence experiment results has not been addressed thoroughly. In the present study, we investigated the hypothesis that different light frequencies and intensities would induce distinct olfactory behaviours. Our results support this hypothesis: same ORNs drove different valence responses to static- or pulsed-light activations; notably, none of the ORNs triggered contrasting valence responses (attraction vs. avoidance), but rather inconsistent results (valent vs. non-valent). We propose that manifold illumination regimes must be utilized to obtain generalizable results in behavioral studies. 


\section{Author contributions}

Conceptualization: TT, ACC; Methodology: TT, ACC;

Experiments: TT, SBB; Software: TT (Python), JS (LabView);

Data Analysis: TT; Hardware: TT, JS; Writing - Original Draft:

TT; Writing - Revision: TT, ACC ; Visualization: TT;

Supervision: ACC; Project Administration: ACC; Funding Acquisition: ACC.

\section{Acknowledgements}

The authors would like to thank Dr. Sangyu Xu for discussions on the manuscript.

\section{Funding}

TT and ACC were supported by grants MOE-2013-T2-2-054 and MOE2017-T2-1-089 from the Ministry of Education, Singapore, and grant RGP0028/2018 from the Human Frontier Science Program. JCS and ACC were supported by grants 1231AFG030 and 1431AFG120 from the A*STAR Joint Council Office. TT was supported by a Singapore International Graduate Award (SINGA) scholarship from the A*STAR Graduate Academy. The authors were supported by a Biomedical Research Council block grant to the Institute of Molecular and Cell Biology, and a Duke-NUS Medical School grant to ACC.

\section{References}

Adamantidis, A. R., Zhang, F., Aravanis, A. M., Deisseroth, K., \& de Lecea, L. (2007). Neural substrates of awakening probed with optogenetic control of hypocretin neurons. Nature, 450(7168), 420-424.

Allen, B. D., Singer, A. C., \& Boyden, E. S. (2015). Principles of designing interpretable optogenetic behavior experiments. Learning \& Memory , 22(4), 232-238.

Banghart, M., Borges, K., Isacoff, E., Trauner, D., \& Kramer, R. H. (2004). Light-activated ion channels for remote control of neuronal firing. Nature Neuroscience, 7(12), 1381-1386. 
Baratz, K. H., Tosakulwong, N., Ryu, E., Brown, W. L., Branham, K., Chen, W., ... Edwards, A. O. (2010). E2-2 protein and Fuchs's corneal dystrophy. The New England Journal of Medicine, 363(11), 1016-1024.

Bell, J. S., \& Wilson, R. I. (2016). Behavior Reveals Selective Summation and Max Pooling among Olfactory Processing Channels. Neuron, 91(2), 425-438.

Bernstein, J. G., \& Boyden, E. S. (2011). Optogenetic tools for analyzing the neural circuits of behavior. Trends in Cognitive Sciences, 15(12), 592-600.

Blumhagen, F., Zhu, P., Shum, J., Schärer, Y.-P. Z., Yaksi, E., Deisseroth, K., \& Friedrich, R. W. (2011). Neuronal filtering of multiplexed odour representations. Nature, 479(7374), 493-498.

Boyden, E. S., Zhang, F., Bamberg, E., Nagel, G., \& Deisseroth, K. (2005). Millisecond-timescale, genetically targeted optical control of neural activity. Nature Neuroscience, 8(9), 1263-1268.

Chong, J. X., Buckingham, K. J., Jhangiani, S. N., Boehm, C., Sobreira, N., Smith, J. D., ... Bamshad, M. J. (2015). The Genetic Basis of Mendelian Phenotypes: Discoveries, Challenges, and Opportunities. American Journal of Human Genetics, 97(2), 199-215.

Chung, S., Weber, F., Zhong, P., Tan, C. L., Nguyen, T. N., Beier, K. T., ... Dan, Y. (2017). Identification of preoptic sleep neurons using retrograde labelling and gene profiling. Nature, 545(7655), 477-481.

Claridge-Chang, A., Roorda, R. D., Vrontou, E., Sjulson, L., Li, H., Hirsh, J., \& Miesenböck, G. (2009). Writing Memories with Light-Addressable Reinforcement Circuitry. Cell, 139(5), 1022.

Clark, D. A., Odell, S. R., Armstrong, J. M., Turcotte, M., Kohler, D., Mathis, A., ... Mathew, D. (2018). Behavior Responses to Chemical and Optogenetic Stimuli in 
Drosophila Larvae. Frontiers in Behavioral Neuroscience, 12, 324.

Clyne, J. D., \& Miesenböck, G. (2008). Sex-specific control and tuning of the pattern generator for courtship song in Drosophila. Cell, 133(2), 354-363.

Couto, A., Alenius, M., \& Dickson, B. J. (2005). Molecular, Anatomical, and Functional Organization of the Drosophila Olfactory System. Current Biology: CB, 15(17), 1535-1547.

Deisseroth, K. (2010). Optogenetics. Nature Methods, 8, 26.

Deisseroth, K. (2015). Optogenetics: 10 years of microbial opsins in neuroscience. Nature Neuroscience, 18(9), 1213-1225.

Faucher, C. P., Hilker, M., \& de Bruyne, M. (2013). Interactions of carbon dioxide and food odours in Drosophila: olfactory hedonics and sensory neuron properties. PloS One, 8(2), e56361.

Fenno, L., Yizhar, O., \& Deisseroth, K. (2011). The development and application of optogenetics. Annual Review of Neuroscience, 34, 389-412.

Fishilevich, E., \& Vosshall, L. B. (2005). Genetic and Functional Subdivision of the Drosophila Antennal Lobe. Current Biology. https://doi.org/10.1016/j.cub.2005.07.066

Guru, A., Post, R. J., Ho, Y.-Y., \& Warden, M. R. (2015). Making Sense of Optogenetics. The International Journal of Neuropsychopharmacology / Official Scientific Journal of the Collegium Internationale Neuropsychopharmacologicum , 18(11), yv079. Haddad, R., Lanjuin, A., Madisen, L., Zeng, H., Murthy, V. N., \& Uchida, N. (2013). Olfactory cortical neurons read out a relative time code in the olfactory bulb. Nature Neuroscience, 16(7), 949-957.

Herman, A. M., Huang, L., Murphey, D. K., Garcia, I., \& Arenkiel, B. R. (2014). Cell type-specific and 
time-dependent light exposure contribute to silencing in neurons expressing Channelrhodopsin-2. eLife, 3, e01481.

Hernandez-Nunez, L., Belina, J., Klein, M., Si, G., Claus, L., Carlson, J. R., \& Samuel, A. D. (2015). Reverse-correlation analysis of navigation dynamics in Drosophila larva using optogenetics. eLife, 4. https://doi.org/10.7554/eLife.06225 Ho, J., Tumkaya, T., Aryal, S., Choi, H., \& Claridge-Chang, A. (2018). Moving beyond P values: Everyday data analysis with estimation plots. bioRxiv. Retrieved from https://www.biorxiv.org/content/early/2018/07/26/377978. abstract

Huber, D., Petreanu, L., Ghitani, N., Ranade, S., Hromádka, T., Mainen, Z., \& Svoboda, K. (2008). Sparse optical microstimulation in barrel cortex drives learned behaviour in freely moving mice. Nature, 451(7174), 61-64.

Jones, W. D., Cayirlioglu, P., Kadow, I. G., \& Vosshall, L. B. (2007). Two chemosensory receptors together mediate carbon dioxide detection in Drosophila. Nature, 445(7123), 86-90.

Katsanis, N. (2016). The continuum of causality in human genetic disorders. Genome Biology, 17(1), 233.

Klapoetke, N. C., Murata, Y., Kim, S. S., Pulver, S. R., Birdsey-Benson, A., Cho, Y. K., ... Boyden, E. S. (2014). Independent optical excitation of distinct neural populations. Nature Methods, 11(3), 338-346.

Kroeger, D., Absi, G., Gagliardi, C., Bandaru, S. S., Madara, J. C., Ferrari, L. L., ... Vetrivelan, R. (2018). Galanin neurons in the ventrolateral preoptic area promote sleep and heat loss in mice. Nature Communications, 9(1), 4129.

Kwon, J. Y., Dahanukar, A., Weiss, L. A., \& Carlson, J. R. (2007). The molecular basis of $\mathrm{CO} 2$ reception in Drosophila. Proceedings of the National Academy of Sciences of the United States of America, 104(9), 3574-3578.

Lewin, K. (1947). Frontiers in Group Dynamics: Concept, 
Method and Reality in Social Science; Social Equilibria and Social Change. Human Relations; Studies towards the Integration of the Social Sciences, 1(1), 5-41.

Lima, S. Q., \& Miesenböck, G. (2005). Remote control of behavior through genetically targeted photostimulation of neurons. Cell, 121(1), 141-152.

Lin, J. Y. (2011). A user's guide to channelrhodopsin variants: features, limitations and future developments. Experimental Physiology, 96(1), 19-25.

Malyshev, A., Goz, R., LoTurco, J. J., \& Volgushev, M. (2015). Advantages and limitations of the use of optogenetic approach in studying fast-scale spike encoding. PloS One, 10(4), e0122286.

Mattis, J., Tye, K. M., Ferenczi, E. A., Ramakrishnan, C., O'Shea, D. J., Prakash, R., ... Deisseroth, K. (2011). Principles for applying optogenetic tools derived from direct comparative analysis of microbial opsins. Nature Methods, 9(2), 159-172.

Midgley, G. (2003). Science as Systemic Intervention: Some Implications of Systems Thinking and Complexity for the Philosophy of Science. Systemic Practice and Action Research, 16(2), 77-97.

Miesenböck, G. (2009). The optogenetic catechism. Science, 326(5951), 395-399.

Miesenböck, G. (2011). Optogenetic control of cells and circuits. Annual Review of Cell and Developmental Biology, 27, 731-758.

Miesenböck, G., \& Kevrekidis, I. G. (2005). Optical imaging and control of genetically designated neurons in functioning circuits. Annual Review of Neuroscience, 28, 533-563.

Mohammad, F., Aryal, S., Ho, J., Stewart, J. C., Norman, N. A., Tan, T. L., ... Claridge-Chang, A. (2016). Ancient Anxiety Pathways Influence Drosophila Defense Behaviors. Current 
Biology: $C B, 26(7), 981-986$.

Mohammad, F., Stewart, J. C., Ott, S., Chlebikova, K., Chua, J. Y., Koh, T.-W., ... Claridge-Chang, A. (2017). Optogenetic inhibition of behavior with anion channelrhodopsins. Nature Methods. https://doi.org/10.1038/nmeth.4148

Mohanty, S. K., \& Lakshminarayananan, V. (2015). Optical Techniques in Optogenetics. Journal of Modern Optics, 62(12), 949-970.

Muenke, M., Schell, U., Hehr, A., Robin, N. H., Losken, H. W., Schinzel, A., ... Malcolm, S. (1994). A common mutation in the fibroblast growth factor receptor 1 gene in Pfeiffer syndrome. Nature Genetics, 8(3), 269-274.

Nagel, G., Brauner, M., Liewald, J. F., Adeishvili, N., Bamberg, E., \& Gottschalk, A. (2005). Light activation of channelrhodopsin-2 in excitable cells of Caenorhabditis elegans triggers rapid behavioral responses. Current Biology: CB, 15(24), 2279-2284.

Packer, A. M., Roska, B., \& Häusser, M. (2013). Targeting neurons and photons for optogenetics. Nature Neuroscience, 16(7), 805-815.

Pulver, S. R., Pashkovski, S. L., Hornstein, N. J., Garrity, P. A., \& Griffith, L. C. (2009). Temporal dynamics of neuronal activation by Channelrhodopsin-2 and TRPA1 determine behavioral output in Drosophila larvae. Journal of Neurophysiology, 101(6), 3075-3088.

Semmelhack, J. L., \& Wang, J. W. (2009). Select Drosophila glomeruli mediate innate olfactory attraction and aversion. Nature, 459(7244), 218-223.

Smear, M., Shusterman, R., O'Connor, R., Bozza, T., \& Rinberg, D. (2011). Perception of sniff phase in mouse olfaction. Nature, 479(7373), 397-400.

Suh, G. S. B., Ben-Tabou de Leon, S., Tanimoto, H., Fiala, A., Benzer, S., \& Anderson, D. J. (2007). Light activation of an innate olfactory avoidance response in Drosophila. Current 
Biology: $C B, 17(10), 905-908$.

Suh, G. S. B., Wong, A. M., Hergarden, A. C., Wang, J. W., Simon, A. F., Benzer, S., ... Anderson, D. J. (2004). A single population of olfactory sensory neurons mediates an innate avoidance behaviour in Drosophila. Nature, 431(7010), 854-859.

Szobota, S., Gorostiza, P., Del Bene, F., Wyart, C., Fortin, D. L., Kolstad, K. D., ... Isacoff, E. Y. (2007). Remote control of neuronal activity with a light-gated glutamate receptor. Neuron, 54(4), 535-545.

Temasek Life Sciences Laboratories. (2018, February 28). Recipe for Drosophila media. https://doi.org/10.5281/zenodo.1185451

Thiese, M. S. (2014). Observational and interventional study design types; an overview. Biochemia Medica: Casopis Hrvatskoga Drustva Medicinskih Biokemicara / HDMB, 24(2), 199-210.

van Breugel, F., Huda, A., \& Dickinson, M. H. (2018). Distinct activity-gated pathways mediate attraction and aversion to CO2 in Drosophila. Nature, 564(7736), 420-424.

Volgraf, M., Gorostiza, P., Numano, R., Kramer, R. H., Isacoff, E. Y., \& Trauner, D. (2006). Allosteric control of an ionotropic glutamate receptor with an optical switch. Nature Chemical Biology, 2(1), 47-52.

Wyart, C., Del Bene, F., Warp, E., Scott, E. K., Trauner, D., Baier, H., \& Isacoff, E. Y. (2009). Optogenetic dissection of a behavioural module in the vertebrate spinal cord. Nature, 461(7262), 407-410.

Zemelman, B. V., Lee, G. A., Ng, M., \& Miesenböck, G. (2002). Selective photostimulation of genetically chARGed neurons. Neuron, 33(1), 15-22.

Zemelman, B. V., Nesnas, N., Lee, G. A., \& Miesenbock, G. (2003). Photochemical gating of heterologous ion channels: remote control over genetically designated populations of 
bioRxiv preprint doi: https://doi.org/10.1101/559674; this version posted February 24,2019 . The copyright holder for this preprint (which was not certified by peer review) is the author/funder, who has granted bioRxiv a license to display the preprint in perpetuity. It is made available under aCC-BY 4.0 International license.

neurons. Proceedings of the National Academy of Sciences of the United States of America, 100(3), 1352-1357. 